\title{
Numerical modelling of foam-cored sandwich plates under high-velocity impact
}

\author{
I. Ivañez, C. Santiuste*, E. Barbero, S. Sanchez-Saez \\ Department of Continuum Mechanics and Structural Analysis, University Carlos III of Madrid, Avda. De la Universidad 30, 28911 Leganés, Madrid, Spain
}

\section{Keywords:}

Sandwich plates

Finite-element analysis

High-velocity impact

Foam core

\begin{abstract}
A B S T R A C T
This paper studies the high velocity impact response of sandwich plates, with E glass fibre/polyester face sheets and foam core, using finite element models developed in ABAQUS/explicit code. The failure of the face sheets was predicted by implementing Hou failure criteria and a procedure to degrade mate rial properties in a user subroutine (VUMAT). The foam core was modelled as a crushable foam material. The numerical models were validated with experimental data obtained from scientific literature. The contribution of the foam core on the impact behaviour was evaluated by the analysis of the residual velocity, ballistic limit, and damaged area.
\end{abstract}

\section{Introduction}

Many structural components in several industrial sectors, mainly transport industry, are designed with requirements of high specific strength and stiffness, and damage tolerance. Com posite sandwich structures with polymer foam core can be used in these applications due to their superior performance in terms of strength and stiffness to weight ratios, ease of manufacturing, and flexibility in design. However, these structures are susceptible to be damaged by impact loading, thus the design process must consider their dynamic and impact behaviour. The impact damage could significantly diminish their strength [1], leading to a limita tion of the use of laminate type composite structures [2]. There is an extensive research on the behaviour of sandwich structures subjected to low velocity impact including the analysis of the influence of the foam core; in contrast, there is a lack of studies about their behaviour under high velocity impacts of low mass fragments, thus the influence of the foam core on the high velocity impact behaviour is still not fully understood [3]. High velocity im pact behaviour differs from the low velocity one; according to the comprehensive review of Abrate [4] high velocity impacts are de fined as those where the ratio between impact velocity and the velocity of compressive waves propagating through the thickness is larger than the maximum strain to failure in that direction. This implies that damage is generated during the first few travels of the compressive wave through the thickness when overall plate mo tion is not yet established. Thus, high velocity impact is a phenom enon controlled by wave propagation, and is essentially independent of boundary conditions, whereas a low velocity im

\footnotetext{
* Corresponding author. Tel.: +34 9162499 20; fax: +34 916248331.

E-mail address: csantius@ing.uc3m.es (C. Santiuste).

URL: http://www.uc3m.es/mma/amm (C. Santiuste).
}

pact is highly influenced by the boundary conditions. Consequently the conclusions drawn in studies on static or low velocity impacts are not applicable to high velocity cases.

Most studies on high velocity impact behaviour of sandwich structures are based on experimental tests [5 8]. Although exper imental studies provide essential information, since impact phe nomena depends on numerous parameters, a comprehensive knowledge of its influence on ballistic behaviour requires a broad test programme, which is time consuming and expensive. There fore the use of theoretical models, analytical [9] and numerical [10], to analyse the perforation of sandwich structures is critical to reduce cost and time in design processes. The main advantage of analytical models is the quick analysis of the influence of differ ent parameters on the high velocity impact behaviour of sandwich structures. However, with these simplified models, it is not possi ble to study in depth the perforation process of a composite sand wich panel with foam core. A finite element (FE) analysis provides with the possibility to model high velocity impact processes, acquiring information about the contribution of the different ele ments of the sandwich panel to the projectile energy absorption process.

An accurate $F E$ analysis of a sandwich structures requires including complex models for the mechanical behaviour of the face sheets as well as the core. The behaviour of laminated com posite materials can be considered lineal elastic until the laminate begins to fail. The damage inflicted on a composite laminate is a complex phenomenon due to the different damage mechanisms that could appear: matrix cracking, tensile and compressive fibre breakage, delamination, etc., which depend on many parameters (fibre and matrix properties, characteristic of the fibre matrix interface, manufacturing process, etc.). The failure of composite laminates can be predicted using three different approaches: frac ture mechanics, failure criteria, and damage mechanics, although 
Table 1

Mechanical properties of E-glass/polyester woven laminate.

\begin{tabular}{ll} 
Density $\left(\mathrm{kg} / \mathrm{m}^{3}\right)$ & $\rho=1800$ \\
Young's modulus (GPa) & $E_{1}=E_{2}=10.1$ \\
Poisson ratio & $v_{12}=0.16$ \\
In-plane shear modulus (GPa) & $G_{12}=3.1$ \\
Interlaminar shear modulus (GPa) & $G_{13}=G_{23}=1.2$ \\
Tensile strength (MPa) & $X_{T}=Y_{T}=367$ \\
Compressive strength (MPa) & $X_{C}=Y_{C}=304$ \\
In-plane shear strength (MPa) & $S_{12}=120$ \\
Interlaminar shear strength (MPa) & $S_{13}=S_{23}=34.3$ \\
\hline
\end{tabular}

in some cases it is possible to combine some of them [11,12]. Of these approaches, failure criteria have demonstrated to be valid in many studies, both under static and dynamic conditions. Many sets of failure criteria can be found in the literature [13,14]. Although some works apply simple failure criteria, such as Tsai $\mathrm{Wu}$ or Maximum Stress criteria to study the energy absorption characteristic of structural elements [15], the complex failure of composite materials requires sets of criteria to predict different failure modes (matrix crack, fibre failure, delamination, etc.) [16]. The most common criteria used in the analysis of impact problems considering different failure mechanisms are those of Hashin [17] and Hou et al. [18], the last one constituting a three dimensional version of Chang Chang criteria [19]. The main advantage of the criteria is that the material properties used can be easily obtained from characterisation tests.

The modelling of the foam core behaviour requires the use of models to reproduce the crushing behaviour of these cellular mate rials. Several approaches to crushing behaviour can be found in the scientific literature. The foam core can be modelled as an isotropic porous solid, with the constitutive description proposed by Desh pande and Fleck [20] which utilises a principal stress yield surface under compression and a quadratic yield surface elsewhere in the stress space [21], or as a homogeneous isotropic material using the Von Mises yield criterion [10]. Some numerical codes have avail able foam models based on critical state theory with adjustments to take into account volumetric effects and a non associative flow rule [22]. In this context, the crushable foam plasticity model implemented in ABAQUS has been validated with experimental re sults obtained from quasi static and low velocity impact tests $[23,24]$; however, the validity of this model to reproduce the high velocity impact behaviour of foam cores has not been studied in depth yet.

The numerical models of foam cored sandwich plates including failure criteria to predict the failure of the composite face sheets, and a crushable foam model for the core, have been applied to the analysis of the quasi static behaviour or the low velocity im pact performance of these structures. However, it is needed to gain knowledge on their response to high velocity impact events, and the contribution of the foam core to the high velocity impact behaviour of a sandwich panel is not well understood. In this work the response of composite sandwich plates with foam core sub jected to high velocity impacts was studied by FE analysis.

The sandwich plates consisted of a PVC foam core, and compos ite face sheets made up of E glass/polyester woven laminate. This combination finds widespread applications in transport industry. The face sheets were modelled as anisotropic laminates, including a failure criteria and a procedure to degrade material properties, and the core material was modelled using a crushable foam plas ticity model. The numerical model of the sandwich structure was validated through the comparison with experimental results from scientific literature [8]. The validated numerical model was used to analyses the contribution of the foam core to the energy absorption capability of the sandwich structure and its influence in the ballis tic limit, the residual velocities and the damaged area.

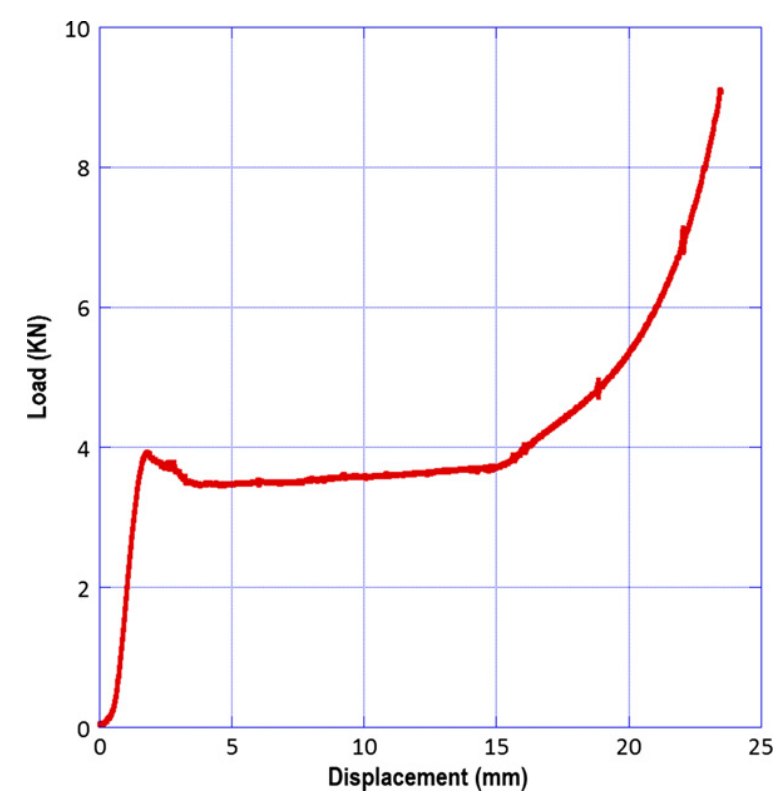

Fig. 1. Load-displacement curve for a compression test of PVC foam.

\section{Numerical model development}

All simulations were carried out with the ABAQUS/explicit fi nite element code [25]. A VUMAT subroutine was developed to model the woven laminate face sheets and the foam core was modelled as a crushable foam material, characterised in uniaxial compression tests.

\subsection{Face sheet model}

The VUMAT subroutine includes a procedure to degrade mate rial properties and the Hou failure criteria [18]. Hou criteria were selected because the mechanical properties required to predict the failure of the material can be obtained by characterisation tests, Table 1 . These criteria include four failure modes: fibre fail ure, matrix cracking, matrix crushing, and delamination. Since Hou model was developed to predict the failure of composite tape plies, in which the fibres are oriented in a single direction, and a

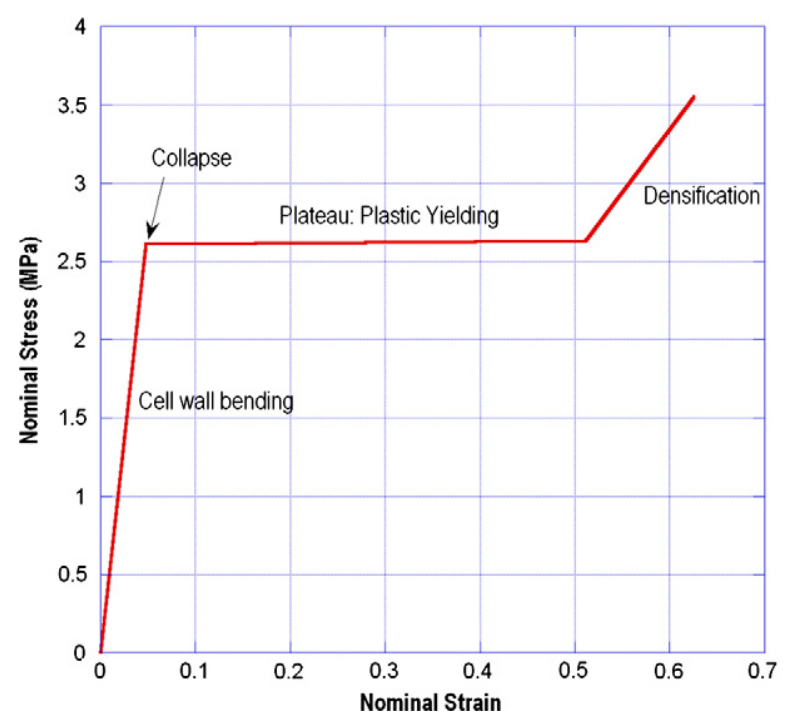

Fig. 2. Nominal stress-strain curve for the PVC foam model. 
(a)

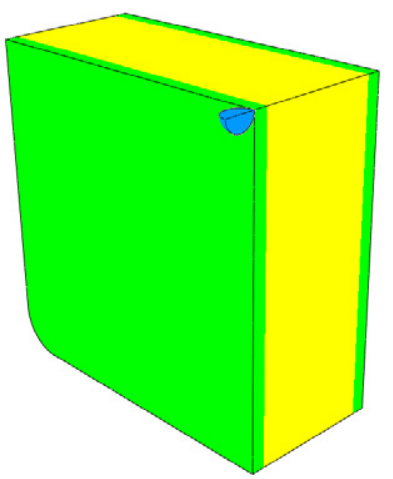

(b)

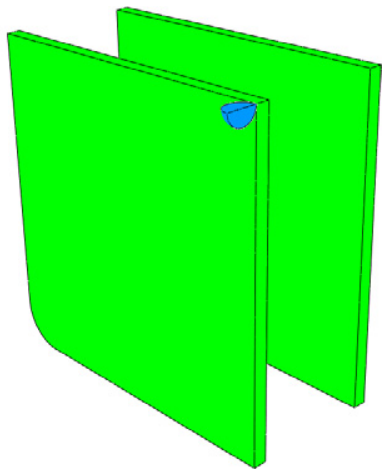

Fig. 3. Structures subjected to high-velocity impact: (a) Sandwich plate and (b) spaced plates.
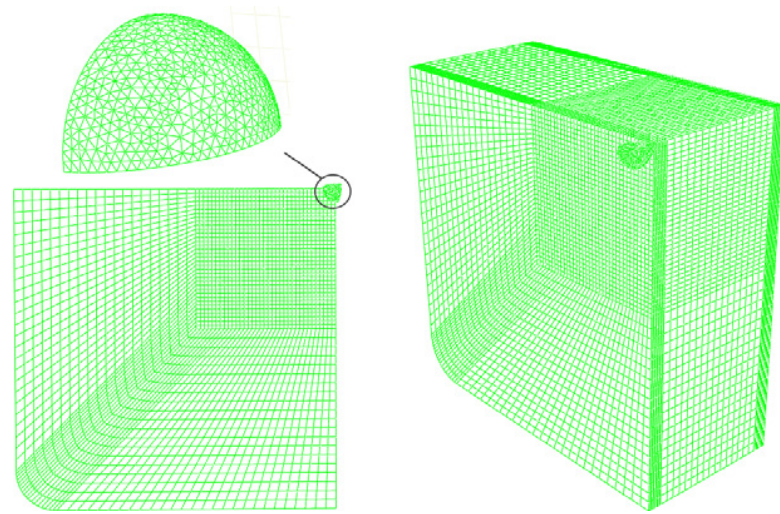

Fig. 4. Sandwich 3D finite-element model.

woven composite ply includes fibres at longitudinal (warp) and at transverse (weft) directions, it was needed to carry out some mod ifications. The matrix failure modes included in the Hou failure cri teria considered that transverse loads are supported by the matrix. However, a woven laminate contains fibres in a transverse direc tion to support theses loads. Thus in this analysis, the fibre failure criterion was applied to longitudinal and transverse directions [26]. In addition, the Brewer and Lagace criterion [27] was included in the subroutine formulation to predict delamination failure, which applies only to normal tensile stress $\left(\sigma_{33}>0\right)$.

Fibre failure in warp direction:

$d_{f 1}^{2} \quad\left(\frac{\sigma_{11}}{X}\right)^{2}+\left(\frac{\sigma_{12}^{2}+\sigma_{13}^{2}}{S_{12}^{2}}\right)$

Fibre failure in weft direction:

$$
d_{f 2}^{2}\left(\frac{\sigma_{22}}{Y}\right)^{2}+\left(\frac{\sigma_{12}^{2}+\sigma_{23}^{2}}{S_{12}^{2}}\right)
$$

Delamination:

$d_{d e l}^{2}\left(\frac{\sigma_{33}}{Z_{r}}\right)+\left(\frac{\sigma_{23}}{S_{23}}\right)^{2}+\left(\frac{\sigma_{31}}{S_{31}}\right)^{2}$

where $X$ is the strength in warp direction and $Y$ the strength in weft direction. The values of these strengths, $X$ and $Y$, are different under tensile or compressive stress, Table $1 . Z_{r}$ is the strength in normal direction, $S_{12}$ is the in plane shear strength, $S_{23}$ is the shear strength in the weft and normal plane and $S_{31}$ is the shear strength in the warp and normal plane.

Under a given load, the stresses at each integration point in the composite structure are computed in the user subroutine. Then,
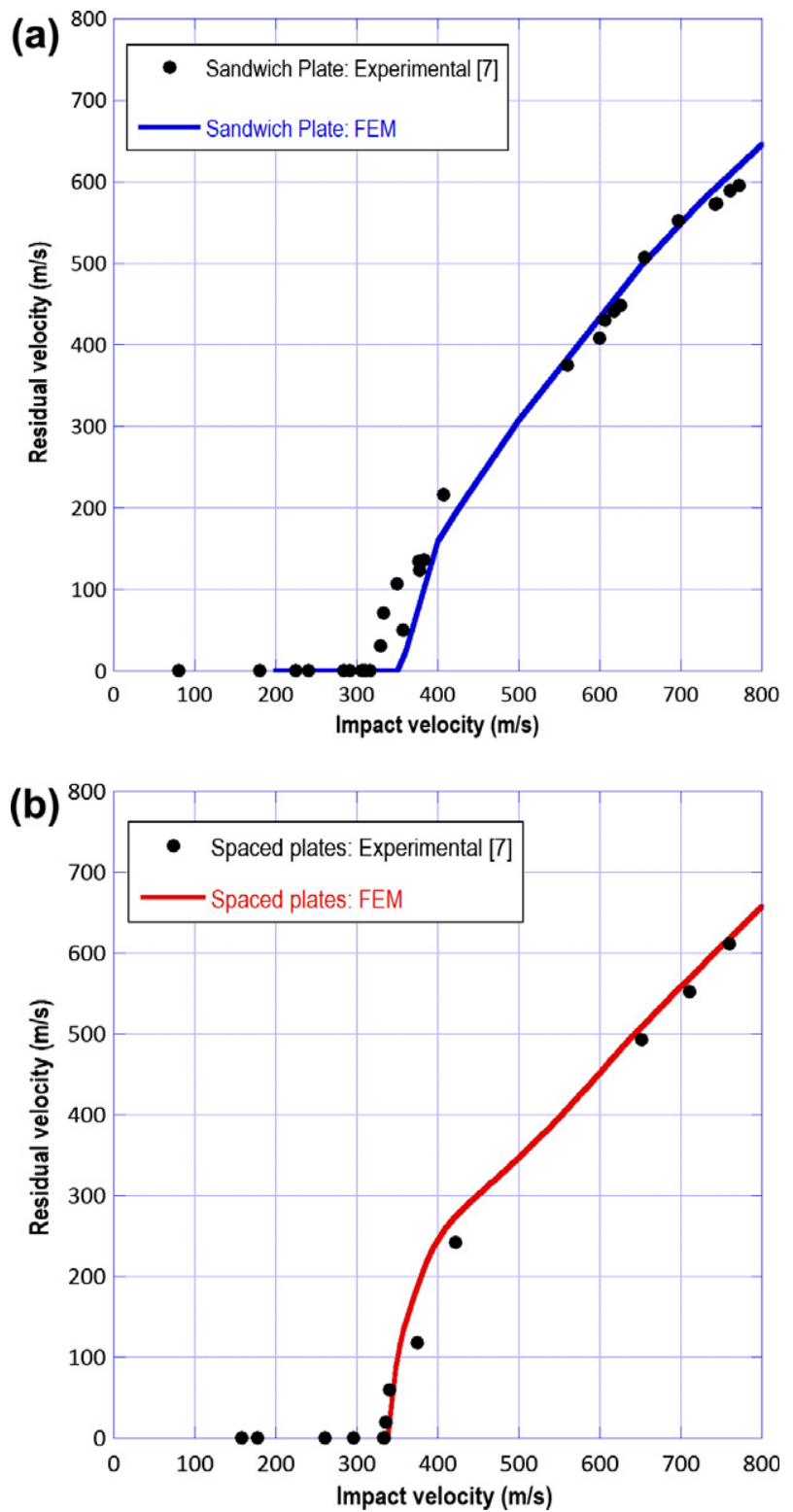

Fig. 5. Residual velocity versus impact velocity: (a) Sandwich plate and (b) spaced plates.

the stresses are substituted into the failure criteria and if any fail ure occurs, the material properties at that point are degraded 


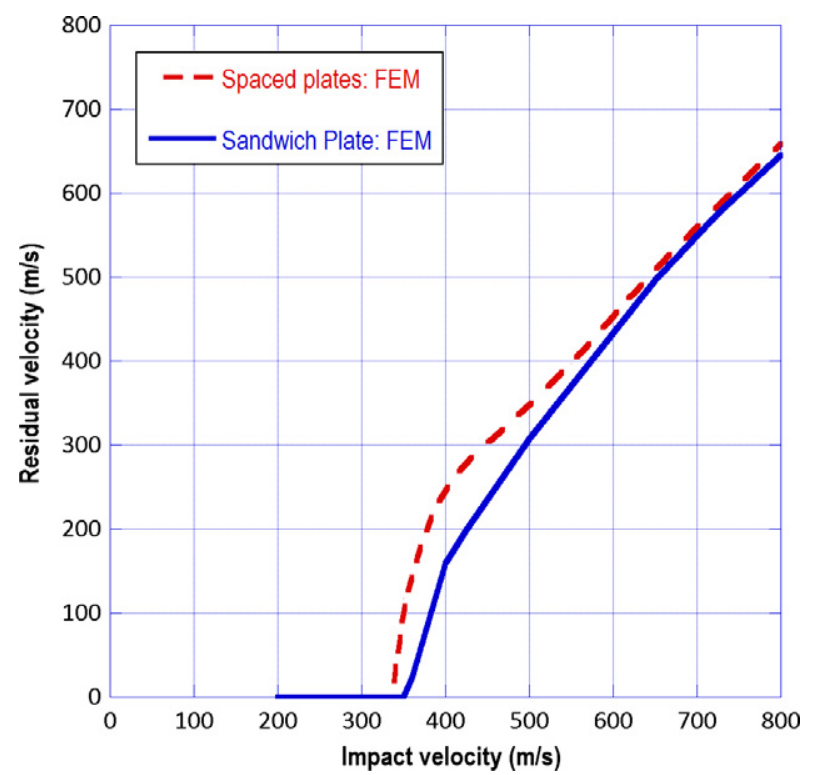

Fig. 6. Residual velocity versus impact velocity.

according to the mode of failure. When the failure criterion is ver ified, the stresses in the damaged area were reduced close to zero to reproduce the elastic property degradation. The updated stres ses depend on the failure mode: a fibre failure produces the com plete collapse of the material at that point $\left(\sigma_{11}=\sigma_{22}=\sigma_{33}=\sigma_{12}=\sigma_{23}=\sigma_{13}=0\right)$, whereas a delamination just avoids supporting stresses in the normal direction $\left(\sigma_{33}=\sigma_{23}=\sigma_{13}=0\right)$.

As the projectile can perforate the composite face sheets during impact, the model requires the use of an element erosion criterion. The stresses on an element damaged drop to near zero while large deformations appear. These elements do not contribute to the strength or the stiffness of the plate, but they can cause lack of con vergence during simulation and instability problems. Maximum strain criteria were implemented in the VUMAT subroutine to re move the distorted elements: after each time increment the longi tudinal strains $\left(\varepsilon_{11}, \varepsilon_{22}\right.$ and $\left.\varepsilon_{33}\right)$ are evaluated, and the element is removed if one of the strains reaches a critical value.

\subsection{Core model}

Several uniaxial compression tests of the foam material were carried out in a servo hydraulic test machine to get a better under stand of the crushable behaviour of the PVC foam core, Fig. 1. These experimental results were used to build a compression stress strain curve of the foam material (Fig. 2) which was implemented in the model. This curve can be divided into three distinct regions. The first stage, corresponds to the elastic region and is determined by the value of the Young's modulus ( $E=87 \mathrm{MPa}$ ). After the yield point $\left(\sigma_{y}=2.63 \mathrm{MPa}\right)$, the elastic region is followed by a yield pla teau, where the stress remains almost constant while the strain is increased. This behaviour is due to the collapse of the cells inside the foam. At the third stage, which corresponds to high compres sive strains, the material reaches a region of densification, causing the stress to increase very quickly. The hypothesis of strain rate independent properties was assumed to model the dynamic foam core behaviour, this hypothesis was demonstrated to be valid to model foam behaviour under low and high velocity impact test $[24,28]$. The crushable foam plasticity model implemented into ABAQUS code was used to model this non homogenous behaviour because it allows defining the crushable behaviour by estimating the compression and hydrostatic yield stress ratios.

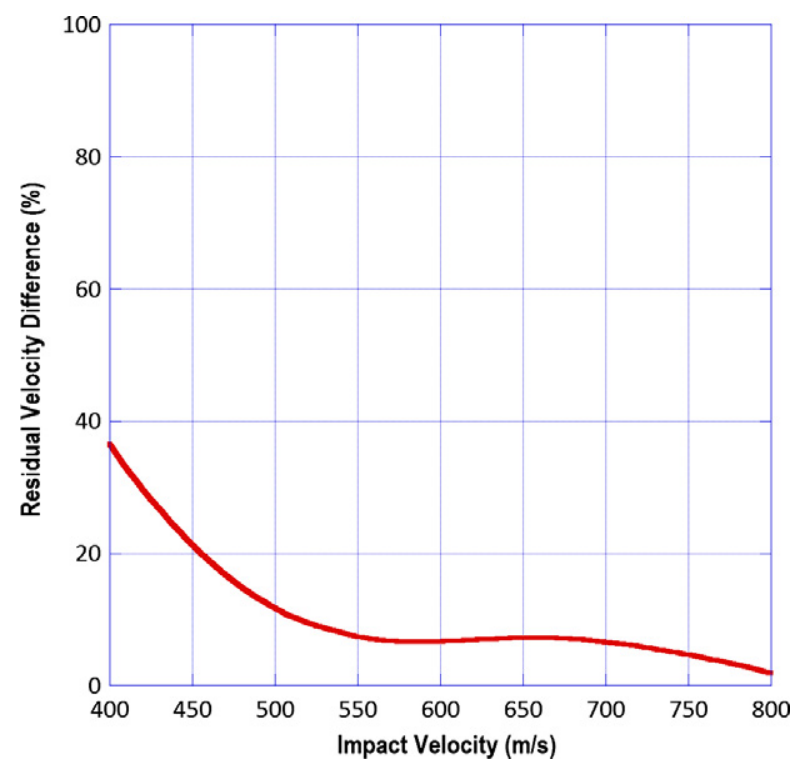

Fig. 7. Differences in the residual velocity between sandwich and spaced plates.

\subsection{High velocity impact test models}

The foam cored sandwich plate analysed in this work consists of two face sheets made up of E glass/polyester woven laminate, with a thickness of $3 \mathrm{~mm}$ and a density of $1800 \mathrm{~kg} / \mathrm{m}^{3}$. The foam core was made up of PVC foam, $30 \mathrm{~mm}$ of thickness and a density of $100 \mathrm{~kg} / \mathrm{m}^{3}$. Despite the selection of high density PVC foam core, the ratio between face sheets and core density is 18 . The plate dimensions were $160 \times 160 \mathrm{~mm}^{2}$ to reproduce the experimental tests obtained from the scientific literature [8]. The sandwich plates were impacted by a steel hemispherical projectile, with a mass of $1.7 \mathrm{~g}$ and a diameter of $7.5 \mathrm{~mm}$. The impact velocity ranged from $80 \mathrm{~m} / \mathrm{s}$ to $780 \mathrm{~m} / \mathrm{s}$.

To study the contribution of the foam core to the high velocity impact response of the sandwich plate, a new structure (spaced plates) consisting of two laminated plates without foam core was

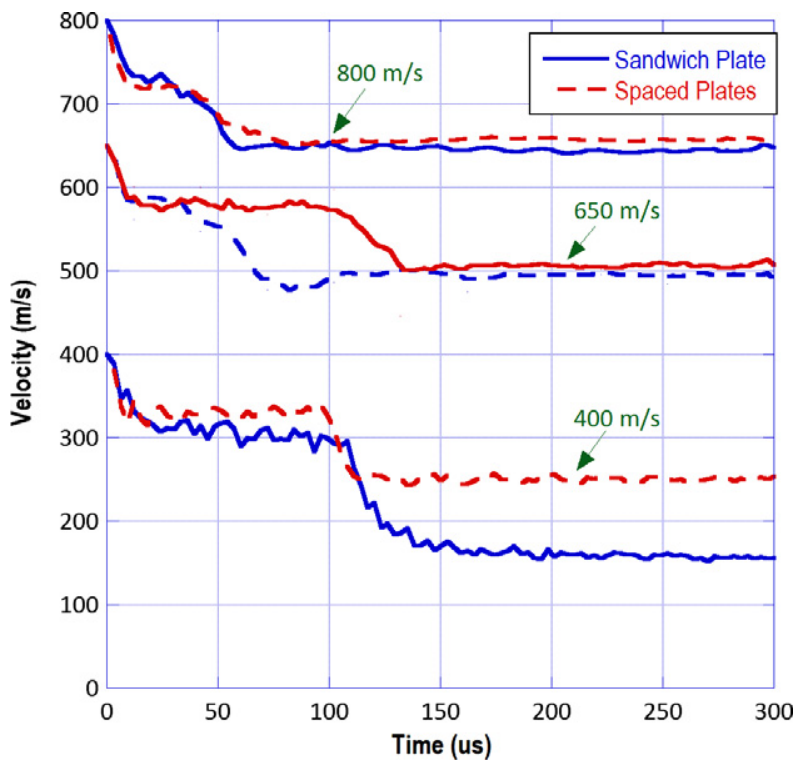

Fig. 8. Projectile velocity versus time. Impact velocity: $400 \mathrm{~m} / \mathrm{s}, 650 \mathrm{~m} / \mathrm{s}$, and $800 \mathrm{~m} / \mathrm{s}$. 


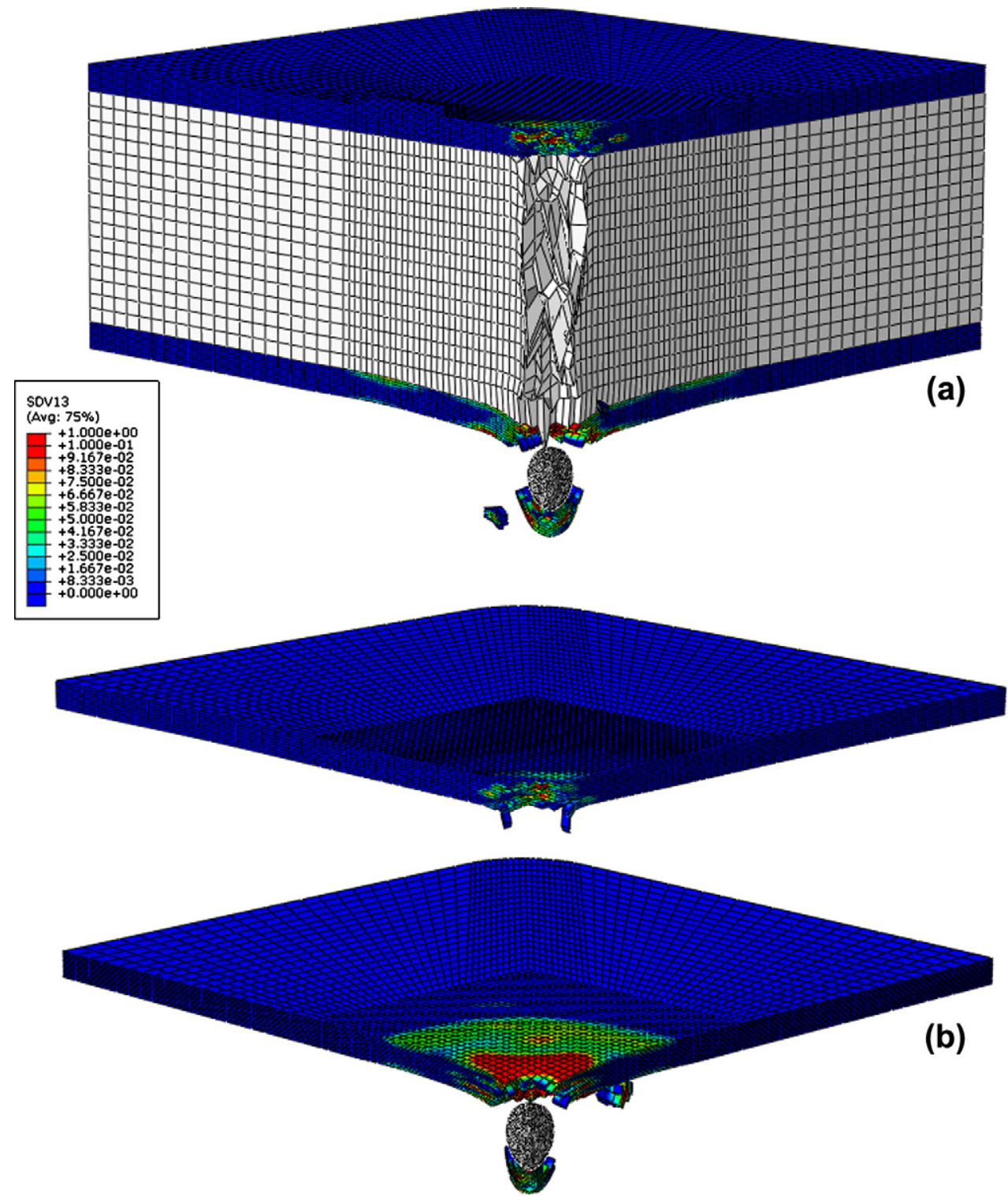

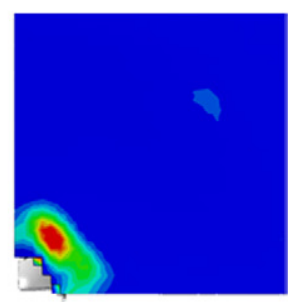

Front face-sheet

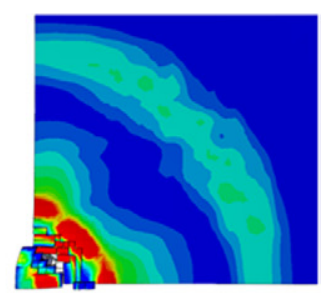

Back face-sheet

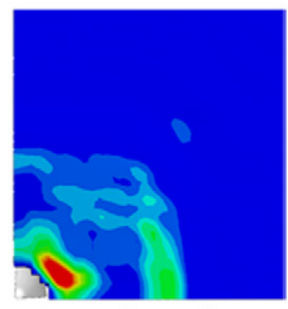

Front face-sheet

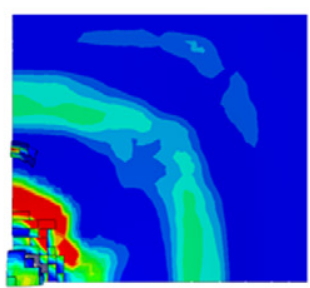

Back face-sheet

Fig. 9. Field of fibre failure criterion after perforation with an impact velocity of $400 \mathrm{~m} / \mathrm{s}$ : (a) Sandwich plate and (b) spaced plates.

also analysed, Fig. 3. In the spaced plates model, the two laminated plates were separated $30 \mathrm{~mm}$ to reproduce the distance between the sandwich face sheets but no interaction between the plates was considered. The influence of the foam core on the high veloc ity impact behaviour of the sandwich plates can be analysed by the comparison between sandwich and spaced plates response.

Since the influence of boundary conditions is usually negligible in high velocity impacts, the simulation included only two solids, representing both the sandwich plate and projectile, Fig. 4. The sandwich plate was considered clamped at its ends to replicate the experimental device, therefore to reproduce the same behav iour in the spaced plates model the face sheets were considered clamped at their ends. The symmetry of the problem permitted to represent only a quarter of the plate and projectile, therefore the size of the analysis domain and the analysis run time were re duced. The projectile was modelled as a linear elastic material ( $E=210 \mathrm{GPa}, v=0.3$ ). It was necessary to define the contact be tween the projectile surface and a node region beneath the impact area and across the sandwich plate. The density of the mesh was refined in the contact area in order to provide detailed information on this region.

Before performing further simulations, the sensitivity of the mesh was evaluated by carrying out successive space discretiza tions and analysing the residual velocity of the projectile and the damaged area in the sandwich plate. The selected mesh consisted of 110,538 elements on the projectile and the sandwich plate ensuring equilibrium between computational efficiency and preci sion of the model in the prediction of residual velocity and dam aged area. The plate was meshed using 94,500 8 node linear hexahedral elements with reduced integration (C3D8R in ABA QUS): 52,500 elements for both face sheets (composed for 10 plies each) and 42,000 elements to define the core. The plate was di vided into two regions, using the structured mesh controls tech nique for meshing the impact region and the sweep technique for the rest. The projectile mesh consisted of 16,038 4 node tetra hedral elements (C3D4 in ABAQUS). 
The same numerical models for the face sheets and projectile were used to simulate the spaced plates behaviour under high velocity impact.

\section{Numerical model validation}

The numerical models for both sandwich plate and spaced plates were validated by comparing its predictions to experimental data obtained from literature [7], in terms of residual velocity and ballistic limit. The ballistic limit was defined in the FE model as the minimum impact velocity required for the projectile to completely penetrate the sandwich plate. Fig. 5 shows the experimental and numerical residual velocity as a function of the impact velocity for the sandwich plates and the spaced plates. Results show very good comparison between the numerical predictions obtained from the FE models and experimental data. The difference between the experimental ballistic limit, $344 \mathrm{~m} / \mathrm{s}$, and the ballistic limit ob
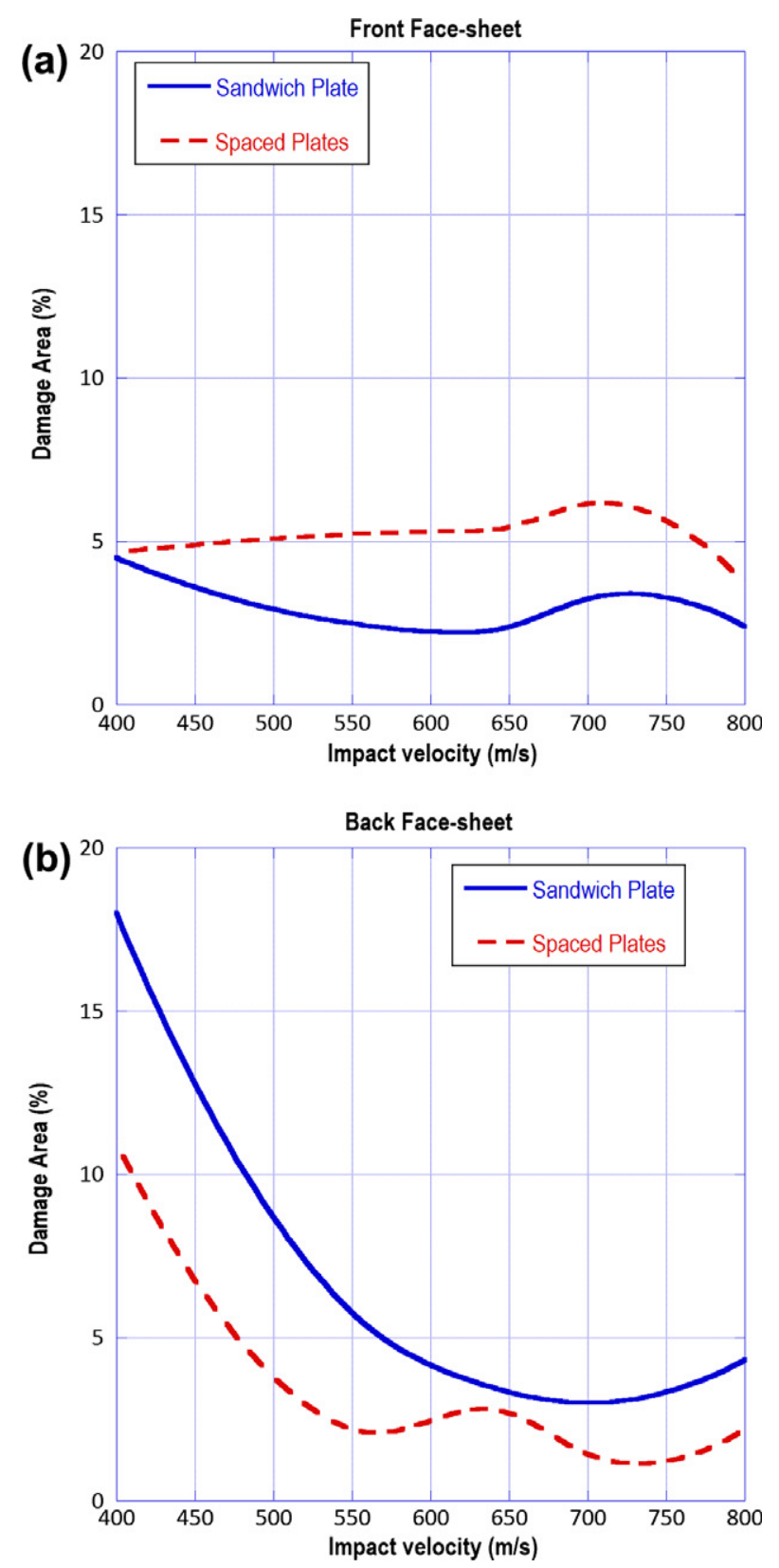

Fig. 10. Damaged area versus impact velocity: (a) Front face-sheet and (b) back face-sheet. tained from the numerical model, $360 \mathrm{~m} / \mathrm{s}$, is of $4.6 \%$ for the sand wich plates, thus the sandwich model shows accurate prediction of ballistic limit. In the case of the spaced plates, the experimental ballistic limit, $335 \mathrm{~m} / \mathrm{s}$, was also in agreement with the numerical result, $345 \mathrm{~m} / \mathrm{s}$, giving a difference of $3.0 \%$. Therefore, good correla tion was found between numerical predictions and experimental results.

\section{Results}

The validated FE models were used to analyse the behaviour of composites sandwich plates with foam core subjected to high velocity impact. To estimate the influence of the presence of the foam core on their impact capability, the high velocity impact behaviour of sandwich plates and spaced plates were compared. Fig. 6 shows the residual velocity curves obtained from both the foam cored sandwich and the spaced plates models. The residual velocity is directly connected with the absorbed energy, thus the differences between the two curves could reveal the contribution of the foam core to the energy absorption process. Although there is a more pronounced separation between the residual velocities at impact velocities close to the ballistic limit, the suppression of the foam core produced a small reduction in the ballistic limit, $4.2 \%$, thus the foam core did not affect significantly to the ballistic limit. It is important to consider the areal density of both models when evaluating this difference: the suppression of the foam core results in an areal density decrease of $20 \%$, from $14.9 \mathrm{~kg} / \mathrm{m}^{2}$ to $11.9 \mathrm{~kg} / \mathrm{m}^{2}$, while the reduction in the ballistic limit is only $4.2 \%$. Thus the inclusion of the core in the sandwich plate cannot be considered effective in terms of increment of the ballistic limit. However, the numerical models showed a significant contribution of the foam core to the reduction of residual velocities and damaged area.

A validated numerical model enables to compare the residual velocity obtained from the sandwich and spaced plates models un der the same impact velocity. Although experimental tests provide considerable information, it is difficult to achieve the same impact velocity with a gas gun for different impact tests, thus it is not pos sible to compare two plates under the same testing conditions. The differences between the residual velocities obtained from the sandwich plates and the spaced plates as a function of the impact velocity, are shown in Fig. 7. When the impact velocity is near to the ballistic limit the differences are significant; the suppression of the foam core means an increment of $36 \%$ in the residual veloc ity, while the reduction in areal density is $20 \%$, indicating that the foam core is effective to increase the energy absorption capability of the sandwich plates for impact velocities slightly above the bal listic limit. However, when the impact velocity is higher, the differ ences are barely perceptible as an indicative of the low influence of the foam core in the energy absorption process.

To gain a better understanding of the interaction between the foam core and the face sheets, the evolution of the projectile veloc ity during the impact event was analysed. Fig. 8 shows the evolu tion of the projectile velocity during the penetration process for three different impact velocities: slightly above and far from the ballistic limit ( $400 \mathrm{~m} / \mathrm{s}$ and $800 \mathrm{~m} / \mathrm{s})$, and an intermediate velocity $(650 \mathrm{~m} / \mathrm{s})$. In each curve, there are three different trends corre sponding to the penetration of the projectile through the three components of the sandwich (front face sheet, core, and back face sheet). In the first region, the front face sheet produced a sud den drop in the velocity of the projectile at the beginning of the im pact event, both in sandwich and spaced plates structures. Secondly, in the sandwich plates, the velocity experienced a slight decrease as the projectile went through the foam core, while in the spaced plates the velocity remained almost constant. Finally, in the back face sheet a new drop in the velocity was observed in both 


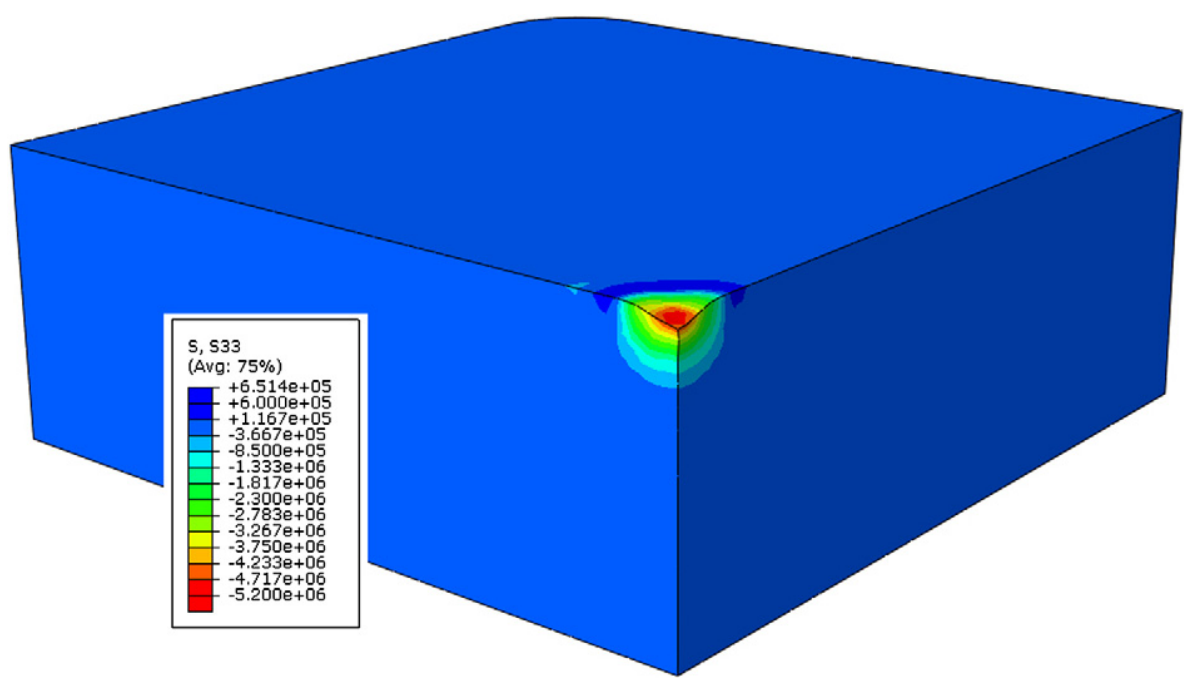

Fig. 11. Through-the-thickness stress field in the foam core during the perforation of the front face-sheet, impact velocity $=400 \mathrm{~m} / \mathrm{s}$.

sandwich and spaced plates structures. It should be notice that this evolution of the velocity during the impact process cannot be analysed experimentally, thus this theoretical models are neces sary to understand the impact behaviour of sandwich structures.

Despite these similar trends, the differences between the im pact behaviour of sandwich and spaced plates varied as a function of the impact velocity. When the impact velocity was near to the ballistic limit $(400 \mathrm{~m} / \mathrm{s})$, significant differences can be found be tween sandwich and spaced plates: the slight contribution of the foam core to the energy absorption process leads to considerable differences in the residual velocity. The observed difference could be explained through the analysis of a monolithic laminate: when the impact velocity is near to the ballistic limit, minor differences in the impact velocity produce important differences in the resid ual velocity. Consequently the inclusion of the foam core produces a slight reduction of the projectile velocity leading to great differ ences in the residual velocity for impact velocities near the ballistic limit. For an intermediate impact velocity $(650 \mathrm{~m} / \mathrm{s})$ there is a dif ferent evolution of the projectile velocity in sandwich and spaced plates, but the residual velocities are similar. On the contrary, for higher impact velocities $(800 \mathrm{~m} / \mathrm{s})$ there is a similar evolution in the projectile velocity leading to similar residual velocities. These slight differences for the highest impact velocities can be explained again with the behaviour of a monolithic laminate: when the im pact velocity is far from the ballistic limit, minor differences in the impact velocity produce insignificant differences in the resid ual velocity.

The failure mechanisms of the composite face sheets were eval uated to analyse the damaged area. Fibre failure was found to be the main failure mechanism both in sandwich and spaced plates. Fig. 9 shows the field of fibre failure criterion on sandwich, Fig. 9a, and spaced plates, Fig. 9b, after perforation with an impact velocity of $400 \mathrm{~m} / \mathrm{s}$. The comparison of the damaged area in sand wich and spaced plates, Fig. 10, revealed that the suppression of the foam core in the sandwich structure affects to the size of the damaged area: in the front face sheet, damage extension is larger on the spaced plates than on the sandwich plate because the foam core restrains the displacement of the front face sheet. On the con trary, the damage is more extensive in the back face sheet of the sandwich structure as a result of the reduction in the velocity pro duced by the presence of the foam core.

The through the thickness stress field in the foam core was plotted to understand the contribution of the foam core to the reduction in the damaged area of the sandwich front face sheet, Fig. 11. During the perforation of this face sheet, high stresses can be found in the vicinity of the impacted zone, thus the foam core was supporting the face sheets, contributing to a reduction in the face sheet deflection and, therefore a reduction in the dam aged area.

\section{Conclusions}

The behaviour of composite sandwich plates subjected to high velocity impact was analysed by performing a 3D finite element model in ABAQUS/Explicit. The composite face sheets behaviour was modelled with a progressive failure damage model based on Hou failure criteria implemented in a VUMAT subroutine. The foam core was performed using the crushable foam plasticity model implemented in the ABAQUS finite element code. The accuracy of the finite element model was determined by comparing experi mental results from literature with numerical predictions in terms of ballistic limit and residual velocity. Satisfactory agreement with the experimental results was found: the numerical simulations were able to predict the ballistic limit with a difference of $4.6 \%$. The material properties used in these models to predict the com posite failure can be easily obtained from characterisation tests.

Combined with the sandwich plate model, a spaced plates model was used to determine the contribution of the foam core to the behaviour of the sandwich structure. The validated FE mod els were used to analyse the contribution of the foam core to the energy absorption capability of the sandwich plates under a high velocity impact. The influence of the core was analysed in terms of ballistic limit, residual velocity, evolution of the projectile velocity, and damaged area. This wide analysis cannot be devel oped experimentally thus these theoretical models are necessary to understand the impact behaviour of sandwich structures.

The numerical study showed that the ballistic limit decreased a $4.2 \%$ with the suppression of the foam core and at impact velocities slightly above the ballistic limit, the residual velocities were in creased significantly (36\%). On the contrary, at much higher impact velocities, most of the impact energy is absorbed by the face sheets and the influence of the foam core is negligible.

Fibre failure was found to be the main failure mechanism in the composite face sheets, both in sandwich and spaced plates struc tures, and it was responsible for the damaged area produced in the face sheets. It was observed that the damaged area was af 
fected by the presence of the foam core. On the front face sheet, the damaged area was increased with the suppression of the foam core because it supported the front face sheet and reduced its deflections. On the back face sheet the damaged area was larger in the sandwich model than in the spaced plates, because the im pact velocity over the back face sheet was lower in the sandwich structure and the damaged area increased when the impact veloc ity was reduced.

\section{Acknowledgement}

The authors are indebted to the Spanish Comisión Interministe rial de Ciencia y Tecnología (Project TRA2007 66555) for the finan cial support of this work.

\section{References}

[1] Ibekwe SI, Mensah PF, Li G, Pang SS, Stubblefield MA. Impact and post impact response of laminated beams at low temperatures. Compos Struct 2007;79:12-7.

[2] Hawyes VJ, Curtis PT, Soutis C. Effect of impact on the compressive response of composite laminates. Compos Part A-Appl Sci 2001;32:1263-70.

[3] Aktay L, Johnson AF, Holzapfel M. Prediction of impact damage on sandwich composite panels. Comput Mater Sci 2005;32:252-60.

[4] Abrate S. Impact on composite structures. Cambridge University Press; 1998.

[5] Vaidya UK, Nelson S, Sinn B, Mathew B. Processing and high strain rate impact response of multi-functional sandwich composites. Compos Struct 2001;52:429-40.

[6] Villanueva GR, Cantwell WJ. The high velocity impact response of composite and fml-reinforced sandwich structures. Compos Sci Technol 2004;64:35-54.

[7] Buitrago BL, García-Castillo SK, Barbero E. Experimental analysis of perforation of glass/polyester structures subjected to high-velocity impact. Mater Lett 2010;64:1052-4.

[8] García-Castillo SK, Buitrago BL, Barbero E. Behaviour of sandwich structures and spaced plates subjected to high-velocity impacts. Polym Compos 2010 doi: $101002 / p c 21047$

[9] Ryan S, Schaefer F, Riedel W. Numerical simulation of hypervelocity impact on CFRP/Al HC SP spacecraft structures causing penetration and fragment ejection. Int J Impact Eng 2006;33:703-12.
[10] Icardi U, Ferrero L. Impact analysis of sandwich composites based on a refined plate element with strain energy updating. Compos Struct 2009;89:35-51.

[11] Allix O, Ladevéze P. Interlaminar interface modelling for the prediction of delamination. Compos Struct 1992;22:235-42.

[12] García-Castillo SK, Sanchez-Saez S, Barbero E, Navarro C. Response of preloaded laminate composite plates subject to high velocity impact. J Phys IV 2006;134:1257-63.

[13] Nahas NM. Survey of failure and post-failure theories of laminated fiberreinforced composites. J Compos Technol Res 1986;8(4):138-53.

[14] Paris F. A study of failure criteria of fibrous composite materials. Technical report: NASA-cr210661; 2001.

[15] Jadhav P, Mantena PR, Gibson RF. Energy absorption and damage evaluation of grid stiffened composite panels under transverse loading. Compos Part B Eng 2006;37:191-9.

[16] Santiuste C, Sanchez-Saez S, Barbero E. A comparison of progressive-failure criteria in the prediction of the dynamic bending failure of composite laminated beams. Compos Struct 2010;92:2406-14.

[17] Hashin Z. Failure criteria for unidirectional fiber composites. J Appl Mech 1980:47(2):329-34.

[18] Hou JP, Petrinic N, Ruiz C, Hallett SR. Prediction of impact damage in composite plates. Compos Sci Technol 2000;60(2):273-328.

[19] Chang F, Chang K. A progressive damage model for laminated composites containing stress concentrations. J Compos Mater 1987;21:834-55.

[20] Deshpande VS, Fleck NA. Multi-axial yield behaviour of polymer foams. Acta Mater 2001;49:1859-66.

[21] Steeves CA, Fleck NA. Collapse mechanism of sandwich beams with composite faces and a foam core, loaded in three-point bending, part II: experimental investigation and numerical modelling. Int J Mech Sci 2004;46:585-608.

[22] Mines RAW, Alias A. Numerical simulation of the progressive collapse of polymer composite sandwich beams under static loading. Compos Part A-Appl Sci 2002;33:11-26.

[23] Sadighi M, Pouriayevali H. Quasi-static and low-velocity impact response of fully backed or simply supported sandwich beams. J Sandw Struct Mater 2008;10:499-524.

[24] Ivañez I, Santiuste C, Sanchez-Saez S. FEM analysis of dynamic flexural behaviour of composite sandwich beams with foam core. Compos Struct 2010;92:2285-91.

[25] Hibbit, Karlsson \& Sorensen, Inc. ABAQUS/explicit user's manual, version 6.4.

[26] Lopez-Puente J, Zaera R, Navarro C. High energy impact on woven laminates. J Phys IV 2003;110:639-44.

[27] Brewer JC, Lagace PA. Quadratic stress criterion for initiation of delamination. J Compos Mater 1988;22:1141-55.

[28] Hoo Fatt MS, Sirivolu D. A wave propagation model for the high velocity impact response of a composite sandwich panel. Int J Impact Eng 2010;37:117-30 